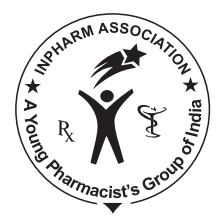

\title{
Drug Attitude and Adherence: A Qualitative Insight of Patients with Hypertension
}

\author{
Saleem F, Hassali MA, Shafie AA, Atif $\mathbf{M}^{1}$ \\ Discipline of Social and Administrative Pharmacy and ${ }^{I}$ Discipline of Clinical Pharmacy, School of \\ Pharmaceutical Sciences, Universiti Sains Malaysia, Penang, Malaysia
}

Address for correspondence: Dr. M Azmi Hassali; E-mail: azmihassali@usm.my

\begin{abstract}
The study is aimed to explore the perceptions and experiences of hypertensive patients toward medication use and adherence. The study was qualitative in nature conducted at Sandamen Provisional Hospital of Quetta city, Pakistan; a public hospital catering to the health needs of about $40 \%$ of the population. A qualitative approach was used to gain an in-depth knowledge of the issues. Sixteen patients were interviewed, and the saturation point was achieved after the $14^{\text {th }}$ interview. All interviews were audio-taped, transcribed verbatim, and were then analyzed for thematic contents by the standard content analysis framework. Thematic content analysis yielded five major themes. (1) Perceived benefits and risks of medications, (2) physician's interaction with patients, (3) perception toward traditional remedies, (4) layman concept toward medications, and (5) beliefs toward hypertension and its control. The majority of the patients carried specific unrealistic beliefs regarding the long-term use of medication; yet these beliefs were heavily accepted and practiced by the society. The study indicated a number of key themes that can be used in changing the beliefs and experiences of hypertensive patients. Physician's attitude, patient's past experiences, and knowledge related to hypertension were noted as major contributing factors thus resulting in nonadherence to therapy prescribed.
\end{abstract}

Key words: Adherence, experiences, hypertension, perception, qualitative

\section{INTRODUCTION}

Hypertension has a persistent, continuous, and independent relationship with the onset of cardiovascular diseases. ${ }^{[1]}$ Even in the presence of evidence-based efficacious antihypertensive agents and guidelines, a

\begin{tabular}{|l|l|}
\hline \multicolumn{2}{|c|}{ Access this article online } \\
\hline Quick Response Code: & \multirow{2}{*}{ Website: } \\
\hline & www.jyoungpharm.in \\
& DOI: \\
\hline
\end{tabular}

large number of patients in clinical practice struggle with uncontrolled hypertension. ${ }^{[2]}$ It was estimated that only $60 \%$ of the patients take their medication as prescribed, ${ }^{[3]}$ and this rate further seems to decline when the studies focus underdeveloped areas. Some studies project this ratio ranging from $50 \%$ to $75 \% .^{[4,5]}$ Multiple factors are identified while addressing this issue but patient nonadherence with medication remains the dominant factor in major healthcare settings. ${ }^{[6]}$ It is important to mention that, in addition to inadequate hypertension control and development of additional disorders, medication nonadherence poses a significant burden on healthcare utilization. Nonadherence results in an unnecessary estimated yearly cost of $\$ 396-\$ 792$ million $^{[7]}$ 
whereas in between one-third and two-third of all medication-related hospital admissions were also attributed to nonadherence. ${ }^{[8,9]}$ This has promoted an interest in using social cognition theories to predict, measure, and understand adherence. ${ }^{[10]}$ Patients' low adherence to medical treatment is seriously undercutting the benefits of medical care, especially in the case of chronic illness and prescribed self-administered medication.

The World Health Organization (WHO) defines adherence as "the extent to which a person's behavior-taking medication, following a diet and/or executing lifestyle changes, corresponds with agreed recommendations from a health care provider". ${ }^{[1]]}$ Adherence is a multifactorial phenomenon and varies from population to population. ${ }^{[12,13]}$ Factors such as age, gender, socioeconomic status and level of disease severity, ${ }^{[14]}$ complexity of prescribed medications, ${ }^{[15]}$ societal acceptance,${ }^{[16]}$ poor patientrelated relationship, cost, forgetfulness, ${ }^{[17]}$ and presence of psychological problems ${ }^{[14]}$ have all been shown to affect the adherence in various populations. Furthermore, the perception of a patient toward medications itself can play a relatively major impact. ${ }^{[18]}$ Studies do reflect the authenticity of the concept as documented in developed countries ${ }^{[19,20]}$ but in the context of developing countries sparse data are available and hence, Pakistan is not an exception.

The major population burden of the world is carried by Asia and thus the frequency of cardiovascular risk is also seen at the higher side. ${ }^{[21]}$ Very poor degree of knowledge regarding hypertension is often reported when the South Asia comes into discussion. ${ }^{[2]}$ Within this context, there is paucity of data about hypertension risk factors, management and treatment not only from major cities of Pakistan but also from tribal residencies with no formal education and having compromised access to healthcare facilities.

The patient's perspective on health and illness has always primarily been taken into account in adherence research, and it is important to explore the perception and understanding of patients for the advice given to them. The most prevalent factor affecting adherence seems to be patients' beliefs about medication and disease. ${ }^{[23]}$ Therefore, to have an in-depth knowledge about hypertensive patient's perception and opinions related to hypertensive treatment and management in Pakistan, this study was undertaken. The study, therefore, highlighted hypertensive patients' perception and experiences about hypertension treatment and management.

\section{MATERIALS AND METHODS}

\section{Study design and settings}

A qualitative approach was used to gain an understanding of patients' perception and experience. The qualitative approach was used because it allows a flexible exploration of respondent's experiences. ${ }^{[24]}$ It also helps to gain understanding of knowledge and coping strategies that quantitative research is unable to uncover, and covers the comprehensive scenario in the research field. ${ }^{[25,26]}$ The study took place in Sandamen Provisional Hospital (SPH, public hospital) of Quetta city, Pakistan; a public hospital catering to the healthcare needs of about $40 \%$ of the population.

\section{Patients}

\section{Inclusion and exclusion criteria}

Patients aging 18 years and above, diagnosed with hypertension and ability to communicate in Urdu (national language of Pakistan), were approached for the study. Immigrants and pregnant ladies were excluded from the study.

Purposive sampling was conducted and the data were collected until saturation was reached and no new findings were drawn. ${ }^{[27]}$ All patients were introduced to the nature of the research prior to the beginning of the interviews. Permission for conducting the interviews was obtained from the Medical Superintendent of the respective hospital. Written consent was also obtained from each of the respondents.

\section{Study procedure and interview process}

A semi-structured interview guide was developed after an extensive literature review. Face and content validity of the guide was performed by experts of Discipline of social and administrative pharmacy, Universiti Sains, Malaysia. The guide was then translated into Urdu. An independent translator was approached for the translation. Interviews with patients were also conducted in Urdu. All interviews were audio-taped and transcribed verbatim by a professional transcriber. Transcripts were verified by the researcher for their accuracy by listening to the tapes. The finalized transcripts were then translated back into English by another independent translator. The first author then analyzed the transcripts line by line, which were read repeatedly and thematically analyzed for their contents. ${ }^{[28]}$ Re-analysis of the themes and contents was done by the co-authors. Each interview lasted approximately 25-30 min. 
To draw in-depth views, the patients were given freedom to express additional reviews and comments. Interviews mainly focused on the perception of patients toward antihypertensive agents, experiences with medications, nature of interaction with healthcare personnel and knowledge toward hypertension.

\section{RESULTS}

Sixteen hypertensive patients (HP1-HP16) were interviewed. The saturation point was achieved at the $14^{\text {th }}$ interview but the interviews were carried on till 16 to assure the emergence of no new themes. Ten patients were drawn from the urban area while six were recruited from the rural locality. Five patients had primary, eight had secondary while three had the bachelor level of education. The duration of hypertension ranged from 1 to 7 years with a mean age of 2.93 years. The number of total medications per day ranged from 1 to 4 , with a mode of three medicines per day. Patients' demographic characteristics are summarized in Table 1. None of the patient had comorbid diseases. During the analysis, five major themes were identified: (1) perceived benefits and risk of medications, (2) physician interaction with patients, (3) perception toward traditional remedies, (4) layman concept toward medications, and (5) believes toward hypertension and its control.

Table 1: Patients' demographic characteristics

\begin{tabular}{lc}
\hline Description & $N$ \\
\hline Sex & 12 \\
Male & 4 \\
Female & \\
Age (years) & 3 \\
$25-34$ & 10 \\
$35-44$ & 3 \\
45 and older & \\
Education level & 5 \\
Primary & 8 \\
Secondary & 3 \\
Bachelor & \\
Duration of disease & 8 \\
1-3 years & 6 \\
4-6 years & 2 \\
More than 6 years & \\
Hypertension control & \\
Adequate (less than $140 / 80 \mathrm{mmHg})$ & 10 \\
Non adequate (More than $140 / 80 \mathrm{mmHg})$ & 6 \\
Total number of medications & \\
Two medications & 4 \\
Three medications & 9 \\
Four medications & 3 \\
Locality & \\
Urban & \\
Rural & \\
\hline &
\end{tabular}

Journal of Young Pharmacists Vol 4 / No 2

\section{Theme 1: Perceived benefits and risks of medications}

In the interviews, patients were asked about their current medications and their perception about the treatment they are undergoing. The majority of the patients stated that medications have more adverse and unwanted effects as compared to the beneficial ones. Even those who did not had this perception believed that the long-term usage of medications can lead to additional physiological abnormalities in addition to the previous ones. Identical conclusion were also reported in studies in developed parts of the world. ${ }^{[29]}$

"Yes. I do use medicines but after all they are chemicals and they do cause damage to body. Continuous use of medicines can cause liver and kidney problems and I do not want an additional disease that is why I limit my use of medicines". HPG

"My brother used medications for three months after an accident and then he developed gastric problems. Now he is always eating tablets or drinking syrup. He cannot eat as be wish and still complains about his stomach. It is all because of the medications he used so I avoid using medications as I do not want to be like bim". HP11

Some patients even stated that medicines are even poisonous in nature. It was observed that the concept of medications is taken inversely by the patients and in major cases they try to avoid using medication.

"Medicines are all bad; they react when they go inside body so you should tell me why I should use a bad thing to correct something that is all ready bad?" HP5

In addition, patients that were using medication quite frequently did express the fear of developing further complications. They admitted that due to the fear of medications being harmful in nature, they often skip a dose or two so they can avoid frequent exposure to medications.

"When I use medicines for one week continuously, my taste becomes bitter. I don't feel hungry and I become lasy. When I give a break in medication, I don't feel such problems. These medicines are destroying my body and I am afraid that with hypertension soon I will have additional problems." HP4

\section{Theme 2: Physician's interaction with the patient}

Regarding patients' views on the physicians' attitude, the majority of the patients stated that they were not satisfied with the way physicians deal with them. They indicated that they could not freely discuss their health status with the doctor. There was clear evidence that the patients did not have good relations with their physicians. It was also 
observed that the patients expected more knowledge from their physicians and the ability to talk about their concerns with healthcare professionals as reported in other studies. ${ }^{[30]}$

"As soon I started using medications, I had some problems. I tried to call the doctor but he did not answer. I managed to reach him at night where he said "I don't see patients at my home". Next day he changed my medicines yet again and charged me fee too and I still have the problem. I think he is testing medicines on me and I don't like this attitude". HP5

"I went to a doctor where I waited for about 2 hours for my check up. The doctor took only about 3-4 minutes and charged me a buge fee. The medicine cost was in addition to it. He even did not listen completely to me. I am sure he is too busy making money so I did not use the medicines". HP14

Patients emphasized the rude and nonfriendly behavior and attitude of physicians as one of the key reasons not to take medications. Patients also highlighted low level of interaction and minimum consultation time, a key problem faced during their visits to the physicians.

"During my last four visits to my physician, he changed my medications thrice and was uncertain about my condition. At time he seemed to be rude too. I observed that he gave me the wrong medications so I quit going to physician and taking those medicines". HP9

Patients who did not have such problems expressed their concern toward little and incomplete information from their physicians regarding hypertension and its treatment.

"After my check up, the physician said to use these medicines and avoid salt, oil and stress. I already knew more than that. What would I have to do if some happens at home? What if my blood pressure is not control? What can I eat, drink, do and etc? He told me nothing and advised me notbing". HPG

\section{Theme 3: Perception toward traditional remedies}

Almost all the patients strongly supported the use of traditional remedies for the control of their condition and stated that only in the case of failure of these remedies they moved to the hospitals. There seemed to be a huge trend toward the use of traditional medications in society not only for hypertension but also a number of other problems too. The use of complementary and alternative medicine is not new and has been reported in a number of studies. ${ }^{[1,32]}$

"I saw my parents treating me and other kids with herbs, home remedies. They said that natural products do not interfere with buman body. I was brought up with the use of these things. Even for hypertension I try traditional products and only visit the doctor when I fell seriously ill'. HP9

"Compare people living in the cities with us (rural). We are strong and heavily built because we are near to nature. We use different herbs and never rush to doctor. That is why we have high resistance against diseases." HP3

"Products that are bitter in taste do well to human body. Take example of garlic! It cleans blood and purifies brain. People in our area use a number of bitter herbs that keep them perfect. I stick to herbs and advice other too". HP7

"I do use medicines prescribed by my physician but at the same time I use some traditional remedies so I can avoid the side effects. My blood pressure was not controlled on medications alone but when I started traditional remedies along with the medications, I faced no problem. It is a good combination". HP10

Religious beliefs also had a strong impact on the patients. The majority of patients stated that diseases can be cured with amulets, sacred water, and religious treatments. ${ }^{[33]}$

"My father and forefathers used to go to the local spiritual healer for treatment. He usually gave some water, amulets and the disease normally eradicated within days. There is health in spiritual healing and almost all of our people prefer to go there and not to the doctor". HPS

\section{Theme 4: Layman concept toward medications}

This theme revealed most interesting ideas and it seemed that the general perception of patient toward medications is quite strange and totally different as compared to its general pharmacology. On the basis of these concepts, the patients hesitated to take medications continuously resulting as a major contributing factor toward nonadherence. Such conclusions were also reported in studies of the same nature. ${ }^{[19]}$

"Medications are hot (warm) in nature. They enter the stomach and increase temperature which interferes with digestion. At the same time, body temperature rises too. The best thing is to avoid use of medications for long and if is too important medications should be used along with milk or cold water to avoid this problem". HP2

"I observed that people who started using medicines developed problems one after another. At first it is one tablet, then two and so on. I am sure these medications are made in such a way. Medications cure one problem and produce another". HP10

Interestingly, patients were more in favor of parental products as compared to other dosage forms. A firm belief was seen regarding the efficacy of parental products and more satisfaction was seen toward intravenous (i.v.) 
preparations. This is a unique observation that was not reported in the studies before.

"Tablets and syrups do nothing good to me. I force physicians to give me injections in blood. My temperature rises, my body stretch up and I feel good in just 10 minutes. The bigger the injection size, better it is, so that is why I trust injections and do not use tablets or syrups". HP4

"When I meet my doctor for blood pressure, he gave me tablets. I asked bim that if he can replace them with injections but he denied. I am sure that tablets have no effect so I don't take them as often". HP9

\section{Theme 5: Beliefs toward hypertension and its control}

Some patients had uncertainties about the treatment and management issue. One common concept that was perceived by the patients was regarding the difference between treatment and management of hypertension. Often at a controlled state the condition was taken as cured by patients and treatment was discontinued.

"Whenever I move out with family, I feel relaxed and my blood pressure remains in controlled range. Even for days I do not take medicines and nothing happens. I think that it is the routine (activities) that controls my blood pressure and not the medications". HP6

"With medicines my blood pressure is controlled. So I normally stop taking my medications. Normally I quit for a week and then start again. Why should I use medicines when I feel ok??" HP12

Some patients considered hypertension, an uncontrollable condition, and stated that it is useless to use medicines as there is no cure and it always become worse with time. This is conflicting to the data that is reported in earlier studies. ${ }^{[34]}$

"I use medicines properly but when I feel sad, or I am doing some important work my blood pressure rises again. My doctor told me that if I use medications properly I won't feel this. It means that this condition is not treatable and whatever I do, it will keep coming back." HP1

"My father had hypertension for 15 years. He was on strict diet plan and used his medication regularly. Even then his blood pressure was not controlled so as I see diet plans, walk, medication, etc. has no effect on bypertension. Once it develops, it is forever and you cannot do anything". HPS

\section{DISCUSSION}

This study highlighted the perception of Pakistani hypertensive patients regarding medication use in hypertension, which was not previously addressed. Medicines for hypertension and other cardio-related disturbances are given out daily to a number of patients every day. The area that is often neglected by physicians is how the patient perceives and acts on the use of medication, or the problems they might experience.

The respondents were found stressed with medicines and had almost similar ideology about this issue. This may be one of the reasons for nonadherence to the medication regimens. Analysis of the interviews further revealed that their knowledge regarding general use and nature of medicines, treatment and control of hypertension was average which is consistent with previous studies conducted in other developing countries. ${ }^{[35]}$ This study also explored multiple factors that can influence compliance behavior in hypertensive patients. The results generally indicated negative feelings toward antihypertensive medications, low awareness about the condition and dissatisfaction with clinical encounters which were also documented in various studies. ${ }^{[36,37]}$

In the context of developing nations such as Pakistan, the health-seeking behavior always occurs in the context of medical pluralism, where the patient will use a different system of healing. In this study, it was obvious that patients focus more on complementary and alternative medicine (CAM) compared to orthodox therapy. Patients made independent but similar assessments regarding the use of modern medicines. It was also observed that orthodox medications do not have such dominance over the population as it is seen in the western world. ${ }^{[38,39]}$ In addition, indigenous healing systems particularly bikmat (Ayurvedic) and spiritual healing are quite prominent in the studied population. There is no official acknowledgment as far as the spiritual healing is concerned; still it is the treatment of choice to the majority of the population.

Insufficient information and understanding was emerged as a major barrier toward the medicine use. Knowledge about the disease and medications used for its treatment was apparently poor, which in turn had a greater impact on patients' adherence to medications. When patients were asked regarding their willingness to earn knowledge about hypertension, its management and medications, their responses were very positive. They stated that this will help them to control their condition. Some of the patients even added that awareness programs shall be implemented at the community level so that the majority of the general population can get benefits from them. This study suggests that there is plenty of room for the improvement in patient-physician interaction and communication, which can lead to better treatment outcomes and positive behavioral changes. This finding 
was consistent with a previous study conducted on an approach toward hypertension treatment. ${ }^{[40]}$ Moreover, the term adherence to treatment was seen unfamiliar among people and this need to be addressed at the earliest stages of treatment as supported by other investigators.

Advancement in preventive and curative health responses needs to be reconsidered. The gap between healthcare professionals and the patients must be narrowed if optimal results need to be achieved. Development of immediate health strategies, policies, and interventions are the utmost demand of the present day, and this development has to move ahead from promises to practices. An important concern in Pakistan is that strategies and policies are delivered centrally and the remote areas are often neglected. There is merely no concept of development or delivery of interventions and the areas that are focused are diseases such as polio, meningitis, or extended program for immunization. Irrespective of living standards, socio-economic standards and life expectancy chronic diseases such as hypertension and diabetes have to be equally addressed in a more systematic and serious manner. Implementation of interventions for increasing awareness on management of diseases and medicines should be extended to areas that have limited access to healthcare facilities. There are chances that these programs can result in dramatic changes in the perception of patients toward medicines and diseases.

Discussions of the advantages and disadvantages of medications in ways that are relevant for individual patients were apparently lacking in the studied population. This needs a complete and quick turnover of the practices that are currently being employed in the healthcare system of Pakistan. Individuals should be educated not only on the risk factors, presenting features and complications of hypertension, but also about the benefits of medications on the treatment outcomes and quality of life. Patients may need to be educated about the differences between curing hypertension and treating it with medications. Efforts to educate the public about lifestyle modifications in the prevention of hypertension and other cardiovascular diseases may also be of utmost importance.

\section{CONCLUSION}

Findings from this research can be utilized in helping doctors and pharmacists who seek to understand their patients' behaviors and attitudes about antihypertensive medications at the start or during the course of treatment. This may be one of the potential areas for future researchers to focus more on patient's behavioral and informational education about the disease and medications in future. In our sample of hypertensive patients, knowledge about medication and disease seems to be poor. Effects of medication and disease, patient-prescriber relationship, social support, and patients' beliefs and attitudes appear to play a role in maintaining adherence. This study identified a number of key themes that might be useful in enhancing the awareness, knowledge, adherence, and attitudes of Pakistani patients with hypertension. To improve behaviors, healthcare providers should improve their relationship with patients. A well-planned educational program is also recommended to educate patients and encourage them to practice a healthy lifestyle. The most important aspect is the need to check on patients' understanding of the information concerning their illness and treatment. Therefore, an assessment of adherence is vital to improve the effectiveness of any educational program on hypertension.

\section{ACKNOWLEDGMENTS}

We acknowledge the patients and hospital practicing staff for their help in the completion of the study.

\section{REFERENCES}

1. Kannel WB. Blood pressure as a cardiovascular risk factor. J Am Med Assoc 1996;275:1571-6.

2. Mohan S, Campbell NR. Hypertension management: Time to shift gears and scale up national efforts. Hypertension 2009;53:450.

3. Nichols-English G, Poirier S. Optimizing adherence to pharmaceutical care plans. J Am Pharm Assoc 2000;40:475-85.

4. Alexander M, Tekawa I, Hunkeler E, Fireman B, Rowell R, Selby JV, et al. Evaluating hypertension control in a managed care setting. Arch Intern Med 1999;159:2673-7.

5. Stockwell DH, Madhavan S, Cohen H, Gibson G, Alderman MH. The determinants of hypertension awareness, treatment, and control in an insured population. Am J Public Health 1994;84:1768-74.

6. Mant J, McManus RJ. Does it matter whether patients take their antihypertensive medication as prescribed? The complex relationship between adherence and blood pressure control. J Hum Hypertens 2006;20:551-3.

7. LaFleur J, Oderda GM. Methods to measure patient compliance with medication regimens. J Pain Palliat Care Pharmacother 2004;18:81-7.

8. McDonnell PJ, Jacobs MR. Hospital admissions resulting from preventable adverse drug reactions. Ann Pharmacother 2002;36:1331-6.

9. Senst BL, Achusim LE, Genest RP, Cosentino LA, Ford CC, Little JA, et al. Practical approach to determining costs and frequency of adverse drug events in a health care network. Am J Health Syst Pharm 2001; 58:1126-32.

10. Hardeman W, Johnston M, Johnston D, Bonetti D, Wareham N, Kinmonth AL. Application of the theory of planned behaviour in behaviour change interventions: A systematic review. Psychol Health 2002;17:123-58.

11. World Health Organization. Chapter XIII Hypertension in Adherence to Long-Term Therapies-Evidence for Action; 2003.

12. DiMatteo MR. Variations in patients' adherence to medical recommendations: A quantitative review of 50 years of research. Med Care 2004;42:200-9.

13. Krousel-Wood M, Hyre A, Muntner P, Morisky D. Methods to improve medication adherence in patients with hypertension: Current status and future directions. Curr Opin Cardiol 2005;20:296-300.

14. Osterberg L, Blaschke T. Adherence to medication. N Engl J Med 2005;353:487-97. 
15. Payne KA, Esmonde-White S. Observational studies of antihypertensive medication use and compliance: Is drug choice a factor in treatment adherence? Curr Hypertens Rep 2000;2:515-24.

16. Lennon C, Hughes CM, McElnay JC, Johnston GD. Identification of psychosocial factors which influence patient adherence with antihypertensive medication. Int J Pharm Pract 2001;9:8.

17. Almas A, Hameed A, Ahmed B, Islam M. Compliance to antihypertensive therapy. J Coll Physicians Surg Pak 2006;16:23-6.

18. Vermeire E, Hearnshaw H, Van Royen P, Denekens J. Patient adherence to treatment: Three decades of research. A comprehensive review. J Clin Pharm Ther 2001;26:331-42.

19. Benson J, Britten N. Patients' decisions about whether or not to take antihypertensive drugs: Qualitative study. BMJ 2002;325:873

20. Kjellgren KI, Svensson S, Ahlner J, Säljö R. Antihypertensive medication in clinical encounters. Int J Cardiol 1998;64:161-9.

21. Pinto RJ. Risk factors for coronary heart disease in Asian Indians: Clinical implications for prevention of coronary heart disease. Indian J Med Sci 1998;52:49-54.

22. Rankin J, Bhopal R. Understanding of heart disease and diabetes in a South Asian community: Cross-sectional study testing the 'snowball' sample method. Public Health 2001;115:253-60.

23. Donovan JL. Patient decision making: The missing ingredient in compliance research. Int J Technol Assess 1995;11:443-55.

24. Berg BL. Qualitative research methods for the social Sciences, $4^{\text {th }}$ ed., Boston: Allyn and Bacon; 2001. p 15-16.

25. Conrad P. Qualitative research on chronic illness: A commentary on method and conceptual development. Soc Sci Med 1990;30:1257-63.

26. Pope C, Mays N. Qualitative research: Reaching the parts other methods cannot reach: An introduction to qualitative methods in health and health services research. BMJ 1995;311:42.

27. Patton MQ. Qualitative research and evaluation methods. $3^{\text {rd }}$ ed. Thousand Oaks, CA: Sage publication; 2002: p 243-245.

28. Hassali MA, Kong D, Stewart K. Generic medicines: Perceptions of consumers in Melbourne, Australia. Int J Pharm Pract 2005;13:257-64.

29. Gascón JJ, Sánchez-Ortuño M, Llor B, Skidmore D, Saturno PJ. Why hypertensive patients do not comply with the treatment. Fam Pract 2004;21:125-30.
30. Morecroft C, Cantrill J, Tully MP, Crossley M. Incongruity: Patients' experiences of hypertension and their general practitioners' perception of their treatment and care. Int J Pharm Pract 2002;10: R65.

31. Clement YN, Morton-Gittens J, Basdeo L, Blades A, Francis MJ, Gomes N, et al. Perceived efficacy of herbal remedies by users accessing primary healthcare in Trinidad. BMC Complement Altern Med 2007;7:4.

32. Shafiq N, Gupta M, Kumari S, Pandhi P. Prevalence and pattern of use of complementary and alternative medicine (CAM) in hypertensive patients of a tertiary care center in India. Int J Clin Pharmacol Ther 2003;41:294-8.

33. Naewbood S, Sorajjakool S, Triamchaisri SK. The role of religion in relation to blood pressure control among a southern California Thai population with hypertension. J Relig Health 2010;1-11. DOI: 10.1007/ s10943-010-9341-z.

34. Wolf-Maier K, Cooper RS, Banegas JR, Giampaoli S, Hense HW, Joffres M, et al. Hypertension prevalence and blood pressure levels in 6 European countries, Canada, and the United States. J Am Med Assoc 2003;289:2363-9.

35. Qureshi NN, Hatcher J, Chaturvedi N, Jafar TH. Effect of general practitioner education on adherence to antihypertensive drugs: Cluster randomised controlled trial. BMJ 2007;335:1030.

36. Svensson S, Kjellgren KI, Ahlner J, Saljo R. Reasons for adherence with antihypertensive medication. Int J Cardiol 2000;76:157-63.

37. Morgan M, Watkins CJ. Managing hypertension: Beliefs and responses to medication among cultural groups. Sociol Health Illn 1988;10:561-78.

38. Bichmann W. Primary health care and traditional medicine-Considering the background of changing health care concepts in Africa. Soc Sci Med 1979;13:175-82.

39. Edwards SD. Traditional and modern medicine in South Africa: A research study. Soc Sci Med 1986;22:1273-6.

40. Jafar TH, Jessani S, Jafary FH, Ishaq M, Orkazai R, Orkazai S, et al. General practitioners' approach to hypertension in urban Pakistan: Disturbing trends in practice. Circulation 2005;111:1278-83.

How to cite this article: Saleem F, Hassali MA, Shafie AA, Atif M. Drug attitude and adherence: A qualitative insight of patients with hypertension. J Young Pharmacists 2012;4:101-7.

Source of Support: No funding was received for this study, Conflict of Interest: The authors declare that there is no conflict of interest.

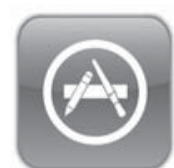

Download iPhone, iPad application
A free application to browse and search the journal's content is now available for iPhone/iPad. The application provides "Table of Contents" of the latest issues, which are stored on the device for future offline browsing. Internet connection is required to access the back issues and search facility. The application is Compatible with iPhone, iPod touch, and iPad and Requires iOS 3.1 or later. The application can be downloaded from http://itunes.apple.com/us/app/medknow-journals/ $\mathrm{id} 458064375$ ? $\mathrm{s}=1 \& \mathrm{mt}=8$. For suggestions and comments do write back to us. 